\title{
Um panorama das tecnologias digitais da informação e comunicação na educação: desafios, habilidades e incentivos estatais
}

\author{
Márcia Gorett Ribeiro Grossi* \\ Carla Fernanda Gonçalves** \\ Sandra Pedrosa Tufy***
}

\section{Resumo}

Este artigo tem como objetivo refletir sobre os novos desafios, as novas habilidades e os incentivos estatais necessários aos professores para utilizarem as Tecnologias Digitais da Informaçáo e Comunicação (TDIC) nos processos de ensino e aprendizagem cujos alunos pertencem a uma nova geração: a geração net. Percebe-se que a educação enfrenta dificuldades para a efetiva e significativa utilização das TDIC no cotidiano das escolas brasileiras e que a maioria dos professores tem recebido uma formaçáo tímida nos cursos de pedagogia nas universidades federais, em relação à apropriação dessas novas tecnologias digitais e suas aplicaçôes pedagógicas relevantes nos contextos escolares. Indicando a necessidade de um olhar mais atento para a formação dos profissionais da educação no que se refere ao uso das TDIC, destaca-se ainda a importância dos incentivos estatais na promoção das políticas públicas voltadas para o uso das Tecnologias Digitais da Informação e Comunicação no desenvolvimento e aperfeiçoamento dos processos de letramento informacional entre os profissionais da educação.

Palavras-chave: Educação. Políticas públicas. Tecnologias digitais.

* Doutora em Ciências da Informação pela Universidade Federal de Minas Gerais (UFMG). Professora Titular do Centro Federal de Educação Tecnológica de Minas Gerais (CEFET/MG).

** Mestre em Ciências da Educação na Pontifícia Universidade Católica de Minas Gerais (PUC/MG).

*** Mestre em Educação pelo Centro Federal de Educação Tecnológica de Minas Gerais (CEFET/MG). 


\section{Introdução}

As Tecnologias Digitais da Informação e Comunicação (TDIC) fortemente presentes na sociedade informacional possibilitam novas dinâmicas sociais que também influenciam o contexto educacional, proporcionando aos educadores (re)pensarem suas práticas pedagógicas, pois, como lembra Lollini (1991), a escola não deve ficar alheia ao mundo da tecnologia uma vez que essa:

Nos fornece antenas, aprimora os nossos sentidos, permite-nos viver em um bem estar com que os nossos antepassados não ousaram sonhar. Um único luxo, porém, não nos é permitido: interromper os nossos processos de aprendizagem, subtrair-nos à formação permanente. Antes a escola era treinamento para a existência, depois instrução e educação em vista do ingresso no mundo do trabalho. Agora é uma necessidade de vida, tanto quanto o ar que respiramos. (LOLLINI, 1991, p. 16).

Diante dessa perspectiva, as TDIC estão sendo inseridas no cotidiano das escolas, seja na esfera das escolas particulares como também nas públicas, auxiliando o professor na sua prática pedagógica e favorecendo a aprendizagem dos alunos. Além disso, o uso das tecnologias na sala de aula contribui com a democratização do acesso à informação, como esclarece Dantas (2005, p. 16):

A escola pode contribuir para a democratização do acesso à informaçáo e às variadas formas de produçáo e disseminação do conhecimento, haja vista que os indivíduos pertencentes a grupos menos favorecidos social e economicamente poderiam ter acesso a estas tecnologias e usufruir os benefícios de sua utilização, fatos que certamente contribuiriam para a diminuição dos riscos de acentuação das desigualdades.

Porém, é fundamental que o professor, como alerta Dantas (2005), sendo o elemento de atuação destacada no processo de ensino e aprendizagem, deve estar preparado para a utilização dessas tecnologias e, não oferecer resistência ao seu uso. Caso contrário, as TDIC não contribuirão com a aprendizagem do aluno.

Para Libâneo (1998), essas resistências existem, pois as tecnologias não são trabalhadas nos processos de formação inicial e contínua do professor e, 
para verificar essa questão, foi realizada uma pesquisa no segundo semestre de 2011, em 42 instituiçóes federais brasileiras, com o objetivo de verificar a existência de disciplinas relacionadas com o uso da das TDIC na educação, especificamente nos cursos de Pedagogia, pois esses são cursos considerados como referência na formação do professor da educação básica. Dentre as 42 instituiçóes pesquisadas, foi possível analisar 31 matrizes curriculares, o que corresponde a $73,81 \%$ do universo estudado.

O resultado comprovou a tímida utilização das TDIC no atual modelo educacional das universidades federais, pois apenas 38,09\% dos cursos de Pedagogia têm disciplinas que preparam estes futuros profissionais para utilizarem essas tecnologias na sala de aula. A pesquisa mostrou também que é na regiāo Sul que a maioria $(83 \%)$ das universidades federais capacita o futuro professor para o uso de tecnologias, seguida pela regiāo Nordeste $(80 \%)$ e pela regiāo Centro-Oeste (75\%).

As principais disciplinas encontradas nas matrizes curriculares desta pesquisa foram: Informática na Educação; Educação e Tecnologia; Tecnologias digitais em Educação; Recursos Tecnológicos na Educação; Educação e Informática; Educação e Novas Tecnologias; Educação e Tecnologias Contemporâneas; Tecnologia Educacional; Software Livre na Educação; Microcomputador na Escola; Acessibilidade e Tecnologia assistida na Educação Inclusiva.

Segundo Libâneo (1996), os pedagogos auxiliam os professores no aprimoramento do seu desempenho na sala de aula, tais como: escolha de conteúdos, de métodos, de técnicas e de formas de organização da classe, dentre outros. Portanto, quando os profissionais da pedagogia estiverem efetivamente preparados para o uso das TDIC na prática educativa, estarão prontos também para colaborar com os professores na apropriação das novas tecnologias, de forma significativa, nas salas de aula.

Assim, a aquisição desses conhecimentos não ficaria a cargo apenas do próprio professor, mas de todos os atores envolvidos no processo de ensino e aprendizagem, trazendo para toda a comunidade escolar a reflexáo e o debate sobre o uso de tecnologias na sala de aula, uma vez que, como afirma Papert (1994, p. 6):

A mesma revoluçấo tecnológica que foi responsável pela forte necessidade de aprender melhor oferece também os meios para adotar açôes eficazes. As tecnologias de 
informação, desde a televisão até os computadores e todas as suas combinaçôes, abrem oportunidades sem precedentes para a ação afim de melhorar a qualidade do ambiente de aprendizagem.

E, afinal, mesmo sendo a integração das tecnologias ao currículo um tema relevante e que esteve presente desde os primeiros projetos relativos ao uso dos computadores na educação, como, por exemplo, o projeto Educom e o projeto Formar, o que se observa é que as tecnologias e o currículo ainda são tratados de maneira distintas e divergentes (ALMEIDA, 2003).

Mesmo com mais de duas décadas de presença de tecnologias na educação, antigas práticas continuam se repetindo. O que se verifica em muitos casos é uma inovação conservadora ainda baseada na tradicional e previsível aula de cinquenta minutos, cuja legitimidade é questionada por uma geração de alunos que vivenciam diariamente experiências de criação, participação e colaboração on-line (CYSNEIROS, 1998).

É evidente, portanto, a necessidade de construir ferramentas de mediação e aprimoramento entre as TDIC e a formação profissional do docente na educação básica, sendo considerada hoje uma questão estratégica para o desenvolvimento econômico do país e para a cidadania do brasileiro, visto que cada vez mais o paradigma informacional se apresenta como estruturador da sociedade contemporânea.

Nesse sentido, Castells (1999) ressalta cinco características desse paradigma: a primeira é a informação considerada como matéria-prima básica; a segunda característica refere-se à penetrabilidade das novas tecnologias informacionais em um número considerável de atividades humanas; a terceira característica diz respeito à adoçáo da lógica de redes em qualquer sistema ou conjunto de relaçóes que utilizam as novas tecnologias da informaçáo, de modo a penalizar com a perda de inúmeras oportunidades àqueles que estiverem desconectados da rede; a quarta característica é baseada na flexibilidade, possibilitando a reversão, modificação e reorganizaçáo de inúmeros processos dentro da rede; e, finalmente, a quinta característica se refere à crescente convergência de tecnologias específicas para um sistema altamente integrado, no qual trajetórias tecnológicas antigas ficam literalmente impossíveis de se distinguir em separado.

Diante desse contexto explanado de maneira lapidada por Castells (1999), fica difícil compreender a demora de inserção da educação nesse processo, 
uma vez que é dentro de seu sistema que ocorre a formação de sujeitos que atuarão e se beneficiarão do universo múltiplo de oportunidades da sociedade informacional. Sendo assim, a educação básica brasileira não pode se furtar a esse diálogo e precisa urgentemente desenvolver experiências de ponta para serem aplicadas ao processo ensino e aprendizagem e dotar os professores e alunos de habilidades refinadas para agir e atuar nessa sociedade informacional.

Segundo Weinberg (2008), o potencial das novas tecnologias deve ser utilizado para modificar o quadro atual de divisão do conhecimento em áreas estanques, às vezes quase incomunicáveis e, para desenvolver habilidades e competências, em vez de treinar os alunos para a execução de tarefas repetitivas. Também Tapscott (2010, p. 30) corrobora com essa ideia quando pontua que:

Aprender uma maneira totalmente nova de se comunicar, acessar informaçốes e se divertir é uma tarefa árdua, e nossos padróes estabelecidos de raciocínio devem mudar para acomodar a nova tecnologia. Para que essa mudança se estabeleça entre os docentes, é preciso esforço pessoal, capacitação profissional e incentivo estatal.

Assim, os professores, enfrentam mais um desafio: lidar com os alunos da geração net, que estão inseridos em um contexto onde a informação é distribuída em variadas mídias em tempo real, de fácil acesso e disponível em praticamente todos os lugares, principalmente com a presença dos telefones e computadores móveis. Esta geração, de acordo com Tapscott (2010), está desenvolvendo e impondo sua cultura a todos, reformulando a maneira como a sociedade e os indivíduos interagem.

Nesse contexto, o problema apresentado neste artigo refere-se à investigação de como os professores podem orientar, mediar e inovar o processo de construção de conhecimento e ao mesmo tempo formar um sujeito cidadão, crítico, participativo e atuante nas relaçóes sociais, inseridos na sociedade da informação, cuja característica marcante é o uso das TDIC, as quais quando bem utilizadas nas salas de aula representam um valioso suporte para a aprendizagem.

$\mathrm{Na}$ busca por alternativas que solucionem este problema, o presente artigo tem como objetivo refletir sobre os novos desafios, as novas habilidades e os incentivos estatais necessários aos professores para utilizarem as Tecnologias Digitais da Informação e Comunicação nos processos de ensino e aprendizagem cujos alunos pertencem a uma nova geração: a geração net. 


\section{Os desafios}

O professor de hoje necessita de novas habilidades para lidar com alunos da geração net. O profissional precisa dotar-se de "superpoderes" para atrair seus educandos e mantê-los no desenvolvimento de processos cognitivos, de inteligências múltiplas e na construção do conhecimento. Como destaca Tepedino (2004, p.18) em seus estudos sobre a formação de professores para o uso das TDIC:

Estamos na era da informação e a cada dia os alunos têm mais fontes de informaçôes ao seu alcance. Entretanto, eles precisam da ajuda dos professores para aprender a interpretar a enorme quantidade de informaçóes que recebem. Os conteúdos se renovam constantemente e as crianças e os adolescentes conquistaram um novo espaço, também são cidadãos de um ciberespaço. Eles sabem operar os computadores melhor do que muitos adultos. Essa nova realidade requer um professor capacitado para lidar com as tecnologias e que possa assumir novos papéis na escola da Sociedade da Informação.

Um dos principais desafios do professor é desenvolver nesses alunos a capacidade de selecionar, dar sentido, utilizar, aplicar e interagir com o grande número de informações disponíveis na internet e nas redes sociais. A todo o momento, o indivíduo é bombardeado por informaçóes que chegam através de textos eletrônicos, vídeos, mensagens on-line, propagandas e pod card, dentre outros.

Assim surgem as questôes: $\mathrm{O}$ quê fazer diante do grande fluxo de conteúdos? Como utilizá-los no processo de ensino e aprendizagem? Como dar sentido a essas informaçôes que chegam muitas vezes de maneira contraditórias e confusas? Fechar os olhos para essas questóes e para as informaçôes que circulam na rede é se colocar à margem desta sociedade informacional, que, segundo Castells (1999), indica o atributo de uma forma específica de organização social em que a geração, o processamento e a transmissão da informação tornam-se as fontes de produtividade e poder devido às novas tecnológicas.

Nesse sentido, Castells (1999) também esclarece que a informação representa o principal ingrediente de nossa organização social e os fluxos de mensagens e imagens entre as redes constituem o encadeamento básico de nossa estrutura social. 
Portanto, para realizar o ofício de ensinar e contribuir principalmente na construçáo do conhecimento, o professor necessita saber acessar a rede, buscar informações atualizadas, envolver-se também no mundo digitalizado no qual o aluno de hoje vive sua maior parte do tempo, conectado na rede.

O professor precisa também estar sintonizado e familiarizado com as mudanças tecnológicas até mesmo para buscar ferramentas que o auxiliem no trabalho de aprendizagem. Entretanto, ressalta-se que a tecnologia, os softwares, os textos e imagens digitais, blogs, os vídeos da internet, os chats, não conseguem sozinhos serem instrumentos na construção do conhecimento. $\mathrm{O}$ professor necessita conhecê-los e, assim, ordená-los, selecioná-los e adaptá-los à proposta do projeto pedagógico e ao contexto social e cultural dos alunos e da escola.

O professor também deve estar pronto e capacitado para saber selecionar essas informaçóes e as ferramentas tecnológicas que podem ser utilizadas em um determinado ambiente, com aquele grupo específico, dependendo daquele conteúdo que se quer trabalhar e dos objetivos pedagógicos propostos, que se quer alcançar. Nesse sentido, Litwin (2001, p. 9) esclarece:

Dispor de informação é uma condição indispensável para que professores e alunos encarem esse grande desafio que é apropriar-se dela. No entanto, a rede de redes não é a única grande provedora de informação. Os manuais, os livros, os jornais, as enciclopédias são produçôes todas elas provedoras de informação. Em alguns casos, essas informaçôes precisam ser adaptadas ao contexto escolar; em outros, são projetadas especificamente como subsídios para o ensino, como os manuais.

Portanto, na sociedade informacional, um dos papéis do professor é desenvolver em seus alunos essa habilidade de lidar com o grande número de informaçóes em variadas mídias e imprimindo nelas um significado. A facilidade de adquirir informaçóes, a rapidez de buscar conteúdos na rede, de copiar e colar textos prontos e disponíveis on-line favorece a autonomia do aluno. Mas essa autonomia da geração net, muitas vezes não está acompanhada de uma postura crítica como deve ter o cidadáo atuante nas relaçóes sociais.

Ao restringir-se a um pequeno espaço da rede, ao fazer leituras superficiais e ao ignorar todo o vasto conteúdo presente na internet, corre-se o risco de formar um sujeito autônomo falseado e superficial. E é aí que surge mais um 
desafio para o professor: desenvolver em seus alunos as habilidades para um pensamento crítico. Habilidades que fazem parte da formação do sujeito em qualquer tempo, mas que hoje se tornaram ainda mais imprescindíveis diante de uma sociedade na qual as informaçóes estão disponíveis, por meio de diversos recursos e em tempo real a estes alunos.

Os professores, enquanto moderadores e incentivadores precisam ajudar este aluno a consolidar essa autonomia fundamentada em uma postura crítica, reflexiva e ativa. No processo de aprendizagem, o professor necessita desta habilidade de instigar e estimular o aluno a fazer escolhas inteligentes, aprimorar o pensamento crítico e desenvolver a capacidade de relacionar as informaçóes e integrá-las ao contexto em que se está inserido.

Os educadores de hoje precisam desenvolver em seus alunos a autonomia com responsabilidade e consciência, elementos essenciais na formação do sujeito, enquanto um ser social ativo e participativo de um mundo globalizado. Principalmente, porque, como lembra Rezende (2012), é o uso intensivo de tecnologias de informação e comunicação que tem diferenciado nossa sociedade de princípios do século XXI.

$\mathrm{O}$ atual cenário de uma sociedade que utiliza as tecnologias em várias atividades, com uma grande oferta de ferramentas e mídias surgindo a todo o momento, dos softwares educacionais disponíveis e do imenso volume de informaçóes na rede, leva-se à falsa crença que o trabalho dos professores é hoje muito mais fácil e prático. Mas o ofício do educador nunca foi fácil e agora requer ainda mais empenho. Na era informacional, além da sua boa formação pedagógica, ele também precisa desenvolver habilidades distintas de ordenar, selecionar, hierarquizar as informaçóes disponíveis e saber lidar com tudo isso para aplicar da melhor maneira possível no processo de ensino e aprendizagem.

Não se deve utilizar uma ferramenta tecnológica, simplesmente porque há uma geração net para ensinar, pois o resultado pode não ser o desejado. Cabe, portanto, ao professor conhecer essas tecnologias para saber qual a sua aplicabilidade, levando-se em consideração as características específicas do grupo de alunos, do conteúdo e das atividades pedagógicas, do contexto social e da realidade da instituição escolar. Para escolher a melhor tecnologia é preciso pesar todos os elementos que compóem o processo pedagógico e de aprendizagem.

Segundo Valente (2007), para que as atividades escolares funcionem, é preciso que os projetos desenvolvidos entre os educandos sejam relacionados 
com a sua realidade e vivência e que o professor, além de disponibilizar os diferentes meios tecnológicos, entenda as especificidades desses meios e saiba usá-los como recursos pedagógicos.

Mais um desafio do professor da sociedade informacional é sem dúvida conseguir tempo suficiente para se tornar um educador atualizado com seu tempo, com acesso às informaçóes, ativo e conhecedor das tecnologias que surgem a todo o momento e em todo lugar. Para lidar com a geraçáo net, que exige rapidez, o educador também deve ser pontual em seu feedback, estar disponível para ajudar o aluno a desenvolver suas tarefas individualmente e colaborativamente, estar presente acompanhando e incentivando os alunos em suas atividades.

$\mathrm{Na}$ busca para atender a essa demanda, que muitas vezes é numerosa e heterogênea, restará ao professor tempo suficiente para ele próprio se capacitar, fazer pesquisas na rede, selecionar um conteúdo mais importante, elaborar suas respostas e aulas, buscar na rede o que é realmente útil e descartar o lixo eletrônico? Ele terá condiçôes de argumentar e motivar esse aluno diante da complexidade do seu trabalho e da quantidade de alunos para atender e incentivar? Por isso, esta profissão precisa ser mais valorizada, como, por exemplo, proporcionando melhores condições de trabalho aos professores, promovendo capacitações e formação continuada, introduzindo na gestão escolar a meritocracia e adoçáo de um piso salarial nacional a carreira docente.

\section{As novas habilidades}

A primeira referência que fundamenta este artigo, e que já foi apresentada anteriormente, é o de sociedade informacional, definida por Araújo e Dias (2005) como a etapa do desenvolvimento da sociedade que se caracterizada pela abundância de informação organizada. Essa sociedade representa uma nova era, na qual as transmissóes de dados são de baixo custo e as tecnologias de armazenamento de dados e informaçóes são amplamente usadas, dentre outras características. Sendo que para transitar adequadamente no interior dessa sociedade é necessário um conjunto de habilidades que os especialistas chamam de letramento informacional (information literacy).

O conceito de letramento vem sendo debatido amplamente em diversas áreas do conhecimento, ou seja, trata-se de uma ação que permite a mobilidade do pesquisador em vários setores (CAMPELLO, 2009). Inúmeras pesquisas 
estão sendo realizadas buscando verticalizar o entendimento sobre o tema.

Vale ressaltar que atualmente têm ocorrido muitos debates sobre letramento matemático, letramento cartográfico, letramento histórico, letramento informacional, dentre outros. Isso significa que as áreas ligadas à educação têm muito a dialogar com a ciência da informação, haja vista que em alguns aspectos as suas pesquisas se complementam, fornecendo instrumental teórico e metodológico que possibilitam um salto qualitativo nas pesquisas.

Para Soares (2006), o letramento é entendido como a capacidade de fazer o uso social competente de múltiplos suportes tecnológicos para agir sobre a informação. A internet, a telefonia móvel, a televisão, o rádio, os comunicadores instantâneos, as redes sociais, os blogs, o livro, entre outros, representam suportes tecnológicos que objetivam a comunicação e transmissão de informações, ou seja, são suportes midiáticos que estão em profundo e constante processo de imbricação.

Atualmente não basta simplesmente saber operar tais ferramentas, é preciso ser capaz de desenvolver aplicaçóes e processos a partir destes instrumentos voltados para as necessidades específicas de cada âmbito da sociedade. A medicina, o mercado financeiro, o cinema e vários outros setores destinam recursos econômicos astronômicos visando desenvolver aplicaçóes para as novas e tradicionais tecnologias, o que significa formar profissionais capazes de oferecer serviços extremamente peculiares e recentes em nossa sociedade.

Portanto, vivenciar uma sociedade informacional significa transitar em meio à abundância da informação e a tecnologia é o instrumento que facilita o acesso e o uso desse universo informacional amplo e complexo. Porém, não se pode esquecer que a tecnologia não é um fim em si mesma, mas um instrumento para melhorar os resultados da aprendizagem e desenvolver propostas relevantes e significativas voltadas para a aplicação da tecnologia informacional no ambiente educacional (CAMPELLO, 2009).

Em síntese, é fundamental desenvolver entre os professores e jovens a habilidade de fazer o uso de diversos suportes midiáticos, compreendê-los, interpretá-los e extrair informaçóes dessas fontes, como afirma Soares (2006). Ou seja, desenvolver a capacidade de tratar qualitativamente a informação em uma sociedade cada vez mais informacional e com vários recursos tecnológicos disponíveis, principalmente a internet. A esse respeito, Rezende (2012, p. 200) lembra que com o uso da Web: 
O mundo configurado para bibliotecas, arquivos e demais locais que detêm informação organizada e estruturada passou a se movimentar na direção de seus usuários. De encastelados, tais locais passaram a buscar cada vez mais a interação com seus usuários/consumidores, buscando saber com maior precisão o quê querem e de que forma querem. Neste horizonte, os serviços prováveis e possíveis são muitos.

\section{Incentivos estatais}

A apresentação feita pelo Ministério da Educação (MEC) do texto preliminar do novo Plano Nacional de Educação (PNE), a vigorar no decênio de 2011 a 2021, cita como problema principal a formaçáo, a qualificação e a valorização do professor em todos os níveis de ensino (BANCO MUNDIAL, 2010).

Essa política pública é parte fundamental na resolução de problemas em um setor estrutural da sociedade brasileira, tanto no que diz respeito a sua responsabilidade na formação de indivíduos capazes de protagonizar papéis de relevância em diversos setores quanto na preparação de mão de obra qualificada dotada de habilidades essenciais para acompanhar os processos de formação continuada em uma economia caracterizada pela constante atualização em seus modos de produção.

Dentro desse contexto, o profissional de educação torna-se um ator crucial para o sucesso de inúmeras políticas públicas que sejam implementadas nos próximos anos. No entanto, o quadro que se verifica atualmente aponta para um patamar preocupante na educação brasileira. As avaliaçóes de massa, nacionais e internacionais, demonstram que, mesmo com os avanços na última década, o estudante brasileiro não possui habilidades nas disciplinas de português, matemática e ciências, colocando-o em níveis educacionais semelhantes aos de países de precária institucionalização e frágil organização social civil.

Os resultados do Brasil no Programa Internacional de Avaliação de Alunos (Pisa) em 2012 confirmam a piora do Brasil em disciplinas relevantes como ciências e leitura (BRASIL, 2012). Os dados revelam que quase metade (49,2\%) dos alunos brasileiros não alcançaram o nível 2 de desempenho na avaliação que tem o nível 6 como teto, ou seja, os estudantes brasileiros não conseguem 
completar itens de leitura, tais como, mostrar uma compreensão detalhada de textos e inferir qual informação é relevante para o item, avaliar criticamente e estabelecer hipóteses, recorrer ao conhecimento especializado e incluir conceitos que podem ser contrários às expectativas. Em relaçâo à Ciências, os dados são mais preocupantes: 55,3\% dos estudantes brasileiros alcançam o nível 1 de conhecimento, indicando a incapacidade desses na aplicaçâo de explicaçôes científicas a situaçốes de seus cotidianos.

Novos dados do Pisa de 2014 mostram que o Brasil está entre os piores no exame, posicionado em $38^{\circ}$ lugar no ranking que avaliou estudantes de 44 países, em três áreas diferentes (OECD, 2014). Também, não são bons os indicadores de aproveitamento em relação aos domínios cognitivos: dos 4.400 alunos que participaram entre redes públicas e privadas, 57\% lembram, $44 \%$ entendem, $30 \%$ aplicam, $15 \%$ analisar, $9 \%$ avaliam e apenas $15 \%$ conseguem criar.

Diante desses dados, que retrata uma triste realidade, não se pode negar que existe um longo caminho a ser trilhado para resolver esses os problemas educacionais, começando com a educação básica, como apontou em 1990 o Fundo das Naçôes Unidas para a Infância (UNICEF):

Políticas de apoio nos setores social, cultural e econômico são necessárias à concretizaçâo da plena provisão e utilização da educação básica para a promoção individual e social. A educação básica para todos depende de um compromisso político e de uma vontade política, respaldados por medidas fiscais adequadas e ratificados por reformas na política educacional e pelo fortalecimento institucional. Uma política adequada em matéria de economia, comércio, trabalho, emprego e saúde incentiva o educando e contribui para o desenvolvimento da sociedade. (UNICEF, 1990).

Também de acordo com a UNICEF (1990), o compromisso político deve ser com a formação do professor. Vale destacar que essa medida não é condição única para a melhoria na educação, mas é de extrema importância. A formação do professor deve ser melhorada, a profissão docente tem que ser valorizada, seja por meio de remuneração adequada e de capacitação continuada, pois parte da fonte dos problemas brasileiros com a educação encontra-se na desatualização dos profissionais da educação, que pelos mais diversos fatores, não encontram 
as condiçōes adequadas para acompanhar as revisōes e debates em suas áreas do conhecimento e inserir tais mudanças em suas práticas de ensino.

O relatório do Banco Mundial, publicado em 21 de dezembro de 2010, aponta quatro desafios cruciais para a educação no Brasil nos próximos dez anos. O primeiro deles é melhorar a qualidade dos professores da educação básica.

Ainda segundo o relatório, a carreira docente não está sendo valorizada e se tornou "uma profissão de baixa categoria", os dados indicam que os professores são recrutados do terço inferior dos estudantes do ensino médio contrastando com a Singapura, Coréia e Finlândia. A melhoria da qualidade dos professores no Brasil exigirá o recrutamento de professores com melhores preparos (BANCO MUNDIAL, 2010).

As TDIC podem contribuir com a capacitação continuada do professor. Nas últimas décadas essas tecnologias vêm cada vez mais se apresentando como ferramentas que auxiliam mediar o processo de ensino e aprendizagem. O que pode ser comprovado através do crescimento vertiginoso da modalidade de Educação a Distância no Brasil. Assim, as TDIC têm muitos pontos positivos, entre eles a possibilidade de reduzir os impactos da dispersão geográfica e assim levar o conhecimento produzido por importantes centros até localidades carentes de instituiçóes formadoras de professores.

A popularização é conseqüente da queda nos preços dos hardwares e softwares fazem com que os custos sejam reduzidos e os resultados extremamente animadores. Porém, um percentual significativo de docentes náo possui o conhecimento necessário para manipular essas ferramentas e mesmo nos cursos de licenciatura de renomadas instituiçóes brasileiras ainda náo se percebe a introdução dessa temática em sua grade curricular.

O quadro apresentado acima permite afirmar que grande parte dos professores brasileiros carece de formação para a apropriaçáo dessas tecnologias e de instrumental teórico e metodológico que produzam aplicaçóes pedagógicas relevantes e significativas em seus contextos de trabalho.

O Relatório do Banco Mundial (2010), segundo análise feita sobre o uso do tempo em sala de aula pelos professores, mostra que os métodos de ensino tradicionais predominam na educação brasileira. Os dados são significativos. $\mathrm{Na}$ média nacional, os livros são utilizados em menos de $20 \%$ do tempo. O quadro negro é o principal material de ensino utilizado entre $25 \%$ e $34 \%$ do tempo destinado à aula. Nenhum material é usado entre $8 \%$ e $21 \%$ do tempo. 
Ainda de acordo com o relatório, praticamente não há a utilização das TDIC e de atividades cooperativas de aprendizagem. Dentre as regióes focalizadas neste artigo estão os Estados de Pernambuco e Minas Gerais, e a capital do Rio de Janeiro, tomados como experiências de referência no cenário educacional nacional. Elas apresentaram, respectivamente, as médias de 3\%, $4 \%$ e $1 \%$, em relação à utilização dessas tecnologias digitais como ferramentas no processo de ensino e aprendizagem.

Ressalta-se que embora os recursos tecnológicos possam proporcionar auxílio e inovação nas práticas pedagógicas, seu uso por si só não se justifica. É fundamental que as TDIC sejam acompanhadas por uma proposta pedagógica adequada às necessidades dos alunos para garantir a melhoria e a qualidade do ensino. $O$ professor precisa aliar o uso das tecnologias com um significado para o aprendizado, conforme sintetizado por Behrens (2000, p. 103), "A inovaçáo não está restrita ao uso da tecnologia, mas também à maneira como o professor vai se apropriar desses recursos para criar projetos metodológicos que superem a reproduçáo do conhecimento e levem à produçáo do conhecimento".

Prosseguindo, Castells (1999), no âmbito da teoria das relaçôes entre a sociedade e a rede, destaca que ao longo da história, o Estado foi a principal força de incentivo e inovação tecnológica, seja interrompendo, seja promovendo, seja liderando a inovação tecnológica, como fator decisivo no processo geral, à medida que expressa e organiza as forças sociais dominantes em um espaço e uma época.

$\mathrm{O}$ autor mostra que a habilidade ou inabilidade de as sociedades dominarem a tecnologia e, em especial, aquelas tecnologias que são estrategicamente decisivas em cada período histórico, traçaria seu destino e expressaria a sua habilidade para impulsionar seu domínio tecnológico por intermédio das instituiçóes sociais (CASTELLS, 1999).

Percebe-se que o MEC tem assumido, há mais de uma década, a responsabilidade pela introdução das novas tecnologias nos ambientes de aprendizagem. E para que tal objetivo seja alcançado é preciso cooptar professores e gestores para que compreendam e utilizem o novo aparato tecnológico e informacional em benefício da educação brasileira. Um desses instrumentos de cooptação é representado pelo Portal do Professor, disponível no site do MEC, que oferece a possibilidade de levar os docentes a descobrir as potencialidades do universo digital a partir da imersão em ambientes virtuais de ensino e aprendizagem. 
O Portal do Professor do MEC, bem como os projetos e políticas públicas que visam uma cultura nacional de informática educativa, podem ser considerados experiências iniciais que tende a ganhar relevância com o crescimento das demandas sociais, sobretudo no que diz respeito à reestruturação de sistema de educação básica.

Trata-se, portanto, de uma política pública genuinamente voltada à disseminação e compartilhamento da informação, objetivando qualificar os profissionais da educaçáo para tratar e agir sobre ela, de modo a utilizar o preparo adquirido nos locais onde lecionam.

Outro exemplo é o Projeto Escolas em Rede, da Secretaria de Estado de Educação de Minas Gerais, que integra o programa de universalização e melhoria do ensino fundamental e médio, cujo objetivo é oferecer às escolas do sistema estadual de ensino oportunidades e condiçóes de atuação de forma mais articulada e cooperativa por meio da cultura do trabalho em rede e a incorporação das TDIC junto às suas atividades educativas e até administrativas.

Além disso, não se pode esquecer da difusão dos softwares livres e da soluçâo do antigo problema da conectividade à rede que tende a ser minimizado com a implementação do Plano Nacional de Banda Larga, cuja proposta é oferecer internet de alta velocidade a custos reduzidos, possam contribuir também para a apropriação das TDIC nas salas de aula no país.

\section{Considerações Finais}

Procurou-se, neste artigo, refletir sobre os novos desafios, as habilidades e os incentivos estatais necessários aos professores para lidar com uma nova geração de aluno, a chamada geração net, e assim fazer uso das TDIC nos espaços de aprendizagem, incorporando essas tecnologias nas práticas educativas.

A educação enfrenta dificuldades para a efetiva e significativa utilização das Tecnologias Digitais da Informação e Comunicação no cotidiano das escolas brasileiras. Um dos primeiros desafios encontrado se refere à tímida inserção dessas tecnologias nos currículos dos cursos de pedagogia das universidades federais brasileiras.

Portanto, acredita-se na necessidade de uma mudança nas matrizes curriculares desses cursos, inserindo disciplinas que preparem os pedagogos efetivamente para o uso das TDIC na prática educativa. Assim, esses profissionais 
estariam qualificados e prontos para auxiliar os professores a utilizarem também as tecnologias, de maneira significativa, nas salas de aula.

Outra ação fundamental para solucionar o problema apresentado é o estudo de uma proposta pedagógica que contemple um diálogo entre os conteúdos das disciplinas, as Tecnologias Digitais da Informação e Comunicação e o contexto social e cultural.

Essas são algumas medidas podem ajudar o professor a ficar apto a enfrentar o desafio de perceber a escola enquanto espaço de construção da cidadania, trazendo a cultura e a realidade dos alunos como ponto de partida do processo ensino e aprendizagem, atuando como motivadores e incentivadores, desenvolvendo nos alunos a capacidade de selecionar, dar sentido, utilizar, aplicar e interagir com o grande número de informaçóes disponíveis na internet e nas redes sociais, ou seja, não se pode ignorar que este é o novo espaço onde estáo inseridos esses alunos pertencentes a geração net.

Além disso, é necessária uma educação continuada, apoiada pelo governo sob a forma de programas educacionais para os professores e demais atores envolvidos no processo educacional das redes públicas.

Desse modo, os professores estarão adquirindo novas habilidades, como compreender, desenvolver e aperfeiçoar os processos de letramento informacional aqui entendido como a capacidade de fazer o uso social competente de múltiplos suportes tecnológicos para agir sobre a informaçáo, voltados para os docentes e gestores. Trata-se de uma açáo estratégica para a melhoria de nossa educaçáo básica, principalmente tendo em vista o efeito mediador e multiplicador que cada profissional devidamente embasado tem dentro da rede de ensino.

Assim, no que diz respeito à grande dificuldade dos docentes na educação básica em incorporar os recursos tecnológicos informacionais como ferramentas cotidianas no contexto escolar, percebe-se por parte dos professores interesse e disposição. Entretanto, é importante destacar que ainda existem obstáculos como: as precárias condiçóes da sala de aula relativas à conectividade com a internet (principalmente nos municípios mais afastados), a insuficiência do suporte técnico, as deficiências na formação dos profissionais da educação e, sobretudo, a ausência de profissionais aptos a desenvolver metodologias e aplicaçôes direcionadas aos contextos educacionais a partir dos diversos suportes midiáticos presentes no mercado. 
É necessário aos profissionais da educação formação para lidar com as tecnologias informacionais em um contexto de rápidos avanços e de intensas demandas sociais e para formar indivíduos capazes de atuar criticamente em ambientes de constantes reformulações. Esta problemática se evidencia ainda mais diante de uma sociedade informacional, onde a principal matéria prima é a informação.

As décadas iniciais de introdução das TDIC na educação básica foram de descoberta e experimentação, direcionando as atençôes para conhecimentos que se limitavam ao funcionamento das máquinas e dos programas. Já a década que se inicia apresenta aos pesquisadores o desafio de desenvolver, a partir das tecnologias disponíveis, aplicaçôes particularmente voltadas ao contexto educacional. Segregar esse processo aos grupos e instituiçôes mais privilegiados significa colocá-los mais uma vez em vantagem competitiva em relação à grande maioria.

Além disso, o momento atual é extremamente favorável à disseminação das tecnologias informacionais devido a um complexo conjunto de interaçóes, tais como a criatividade, a iniciativa empreendedora, condiçôes técnicas, pesquisas científicas, apoio estatal, entre outras, como afirma Castells (1999).

\section{REFERÊNCIAS}

ALMEIDA, Maria Elizabeth Bianconcini. Tecnologias e currículo: trajetórias convergentes ou divergentes? São Paulo: Paulus, 2011. p. 6-8.

ARAÚJO, Eliany Alvarenga; DIAS, Guilherme Atayde. A atuação profissional do bibliotecário no contexto da sociedade de informação: os novos espaços de informação. In: OLIVEIRA, Marlene de (Org.). Ciência da Informação e Biblioteconomia: novos conteúdos e espaços de atuação. Belo Horizonte: Editora da UFMG, 2005. p.110-122.

BANCO MUNDIAL. Atingindo uma educação de nivel mundial no Brasil: próximos passos Washington: Banco Mundial, 2010. Disponível em <http://siteresources.worldbank.org/BRAZILINPOREXTN/ Resources/38171661293020543041/ESummary_Atingindo_Educacao_ nivel_Mundial_Brasil_DEZ2010.pdf>. Acesso em: 20 set. 2011.

BEHRENS, Marilda Aparecida. Projetos de aprendizagem colaborativa num paradigma emergente. In: MORAN, José Manuel. Novas tecnologias e mediação pedagógica. Campinas: Papirus, 2000. 
BRASIL. Ministério da Educação. Relatório Nacional PISA 2012: resultados brasileiros. Brasília, DF: MEC; INEP, 2012. Disponível em: <http:// download.inep.gov.br/acoes_internacionais/pisa/resultados/2014/relatorio_ nacional_pisa_2012_resultados_brasileiros.pdf>. Acesso em: 19 jan. 2014.

CAMPELLO, Bernadete Santos. Letramento informacional no Brasil: práticas educativas de bibliotecários em escolas de ensino básico. 2009. 209 f. Tese (Doutorado em Ciência da Informação) - Universidade Federal de Minas Gerias, Belo Horizonte, 2009.

CASTELLS, Manuel. A sociedade em rede. São Paulo: Paz e Terra, 1999.

CYSNEIROS, Paulo Gileno. Novas Tecnologias na sala de aula: Melhoria do Ensino ou Inovação Conservadora? In: ENCONTRO NACIONAL DE DIDÁTICA E PRÁTICA DE ENSINO, 9., 1998, São Paulo. Anais... São Paulo: FEUSP, 1998, p. 199-216.

DANTAS, Aleksandre Saraiva. A formação inicial do professor para o uso das tecnologias de comunicação e informação.Holos, Ntal, RN, ano 21, maio 2005. Disponível em: <http://www2.ifrn.edu.br/ojs/index.php/HOLOS/article/ viewFile/53/57>. Acesso em: 19 jan. 2014.

LIBÂNEO, José Carlos. Que destino os educadores darão à pedagogia? In: PIMENTA, Selma Garrido (Org.). Pedagogia, ciência da educação? São Paulo: Cortez, 1996. p. 107-134.

LIBÂNEO, José Carlos. Adeus professor, adeus professora? Novas exigências educacionais e profissão docente. 2. ed. São Paulo: Cortez, 1998. (Coleção Questôes da Nossa Época).

LITWIN, Edith. A educação em tempos de internet. Revista Pedagógica Pátio, Porto Alegre, Ano V, n. 18, out. 2001. Disponível em <http://www.revistapatio. com.br/numeros_anteriores_conteudo.aspx?id=234>. Acesso em: 12 set. 2011.

LOLLINI, Paolo. Didática e computador: quando e como a informática na escola. São Paulo: Ediçóes Loyola, 1991. (Coleção Realidade Educacional).

OECD. Organisation for Economic Co-operation and Development. Singapore and Korea top OECD's first PISA problem-solving test. Paris, 1 abr. 2014. Disponível em: <http://www.oecd.org/education/singapore-andkorea-top-first-oecd-pisa-problem-solving-test.htm>. Acesso em: 2 abr. 2014 . 
PAPERT, Seymour. A máquina das crianças: repensando a escola na era da informática. Tradução de Sandra Costa. Porto Alegre: Artes Médicas, 1994.

REZENDE, Eliana Almeida de Souza. Os historiadores e suas fontes em tempos de Web 2.0. Cadernos do CEOM, Chapecó, SC, v. 25, n. 36, 2012. Disponível em: <http://bell.unochapeco.edu.br/revistas/index.php/rcc/ article/view/1160>. Acesso em: 20 jan. 2014.

SOARES, Magda. Letramento: um tema em três gêneros. 2. ed. Belo Horizonte: Autêntica, 2006.

TAPSCOTT, Don. A hora da geração digital. Rio de Janeiro: Agir Negócios, 2010.

TEPEDINO, Simone Abichara Santos. A autoformação do professor para uso de tecnologias digitais na educação. 2004. 103f. Dissertaçáo (Mestrado em Educação) - Pontifícia Universidade Católica de Minas Gerais, Belo Horizonte, 2004.

UNICEF. Declaração Mundial sobre Educação para Todos. Jomtien, mar. 1990. Disponível em: <http://www.unicef.org/brazil/pt/resources_10230.htm>. Acesso em: 20 jan.. 2014.

VALENTE, José A. As tecnologias digitais e os diferentes letramentos. Revista Pedagógica Pátio, Porto Alegre, ano 11, n. 44, nov. 2008. Disponível em: <http://www.revistapatio.com.br/sumario_conteudo.aspx?id=597>. Acesso em: 10 set. 2011.

WEINBERG, Monica. Medir para avançar rápido. Veja, São Paulo, n. 6, p. 17-21, 2008. 
Una visión general de las Tecnologías Digitales de la Información y la Comunicación en la educación: desafíos habilidades e incentivos estatales

\section{Resumen}

Este artículo tiene como objetivo reflexionar sobre los nuevos desafíos habilidades e incentivos estatales necesarios para los profesores que utilizan las tecnologías digitales de la información y la comunicación (TDIC) en el proceso de enseñanza y aprendizaje con los estudiantes que pertenecen a una nueva generación: generación net. Se percibe que la educación enfrenta novos desafios para un uso eficaz y significativa de las TDIC en la vida cotidiana de las escuelas brasileńas, y que la mayoría de los maestros en Brasil tiene recibido una formación frágil en los cursos de pedagogía en las universidades federales, con respecto a apropiación de estas tecnologías digitales y sus aplicaciones pedagógicas pertinente en el contexto escolar. Indicando la necesidad de una mirada más cercana a la formación de los profesionales de la educación con respecto el uso de las TDIC, también hacemos hincapié en la importancia de los incentivos del gobierno para la promoción de políticas públicas para el uso de las tecnologías digitales de
An overview of the Digital Technologies of Information and Communication in the Education: challenges, skills and State incentives

\begin{abstract}
This article aims to reflect on the new challenges, new skills and state incentives necessary for teachers to use the Digital Technologies of Information and Communication (TDIC) in the process of the teaching and learning whose students belong to a new generation: net generation. The education is facing difficulties for effective and meaningful use of TDIC in Brazilian schools, and most teachers has received a fragile training in pedagogy courses in the federal universities, regarding the appropriation of these new technologies and their relevant teaching applications in school contexts. By indicating the need for a closer look at the training of education professionals with regard to the use of the TDIC, we also emphasize the importance of state incentives on the promotion of public policies for the use of Digital Technologies of Information and Communication and the development and improvement of the processes of information literacy among education professionals.
\end{abstract}

Keywords: Education. Public policies. Digital technologies. 
la información y la comunicación en el desarrollo y la mejora de procesos y la información entre los profesionales de la educación.

Palabras claves: Educación. Políticas públicas. Tecnologias Digitales.

\section{Márcia Gorett Ribeiro Grossi}

E-mail: marciagrossi@terra.com.br

\section{Carla Fernanda Gonçalves}

E-mail: carlahistoria@yahoo.com.br

\section{Sandra Pedrosa Tufy}

E-mail: sandrapedrosat@gmail.com

Enviado em: 12/10/2012

Versão final: 26/1/2014

Aprovado em: 1/2/2014 